\title{
O Desafio da Convivência: Assessoria de Diversidade e Apoio aos Cotistas (2004-2008)
}

The Challenge Of Conviviality: Advisory For Diversity And Support To Quota Holders (2004-2008)

El Desafío De La Convivencia: Asesoría De Diversidad Y Apoyo A Los Cotizantes (2004-2008)

Jaqueline Gomes de Jesus

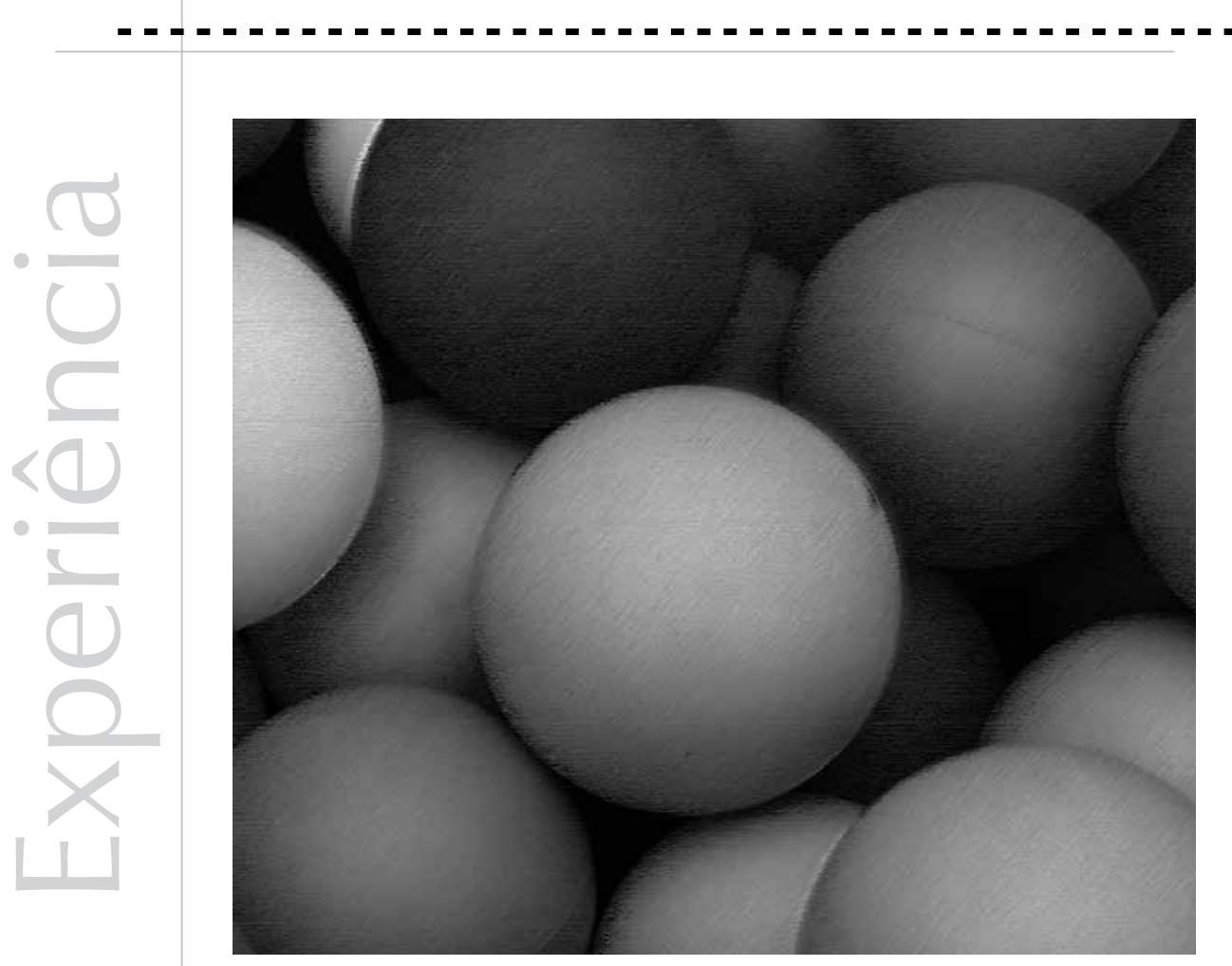


Resumo: Em 2003, a Universidade de Brasília adotou uma política de ações afirmativas para pessoas negras, o Sistema de Cotas para Negros. Em 2004, foi criada a Assessoria de Diversidade e Apoio aos Cotistas ADAC. Ante à demanda do movimento social por uma sala de apoio aos estudantes, desenvolveu-se o Centro de Convivência Negra - CCN, espaço aberto a toda a comunidade acadêmica. O presente artigo apresenta a experiência da ADAC até 2008 e analisa os desafios da convivência entre estudantes cotistas e o espaço acadêmico a partir de pesquisa qualitativa sobre percepções, sentimentos e expectativas acerca do $\mathrm{CCN}$, na forma de questionários com uma pergunta de evocação ao $\mathrm{CCN}$, aplicados a 35 estudantes universitários oriundos do Sistema de Cotas para Negros frequentadores do CCN. Os dados de evocação foram analisados utilizando-se o software Evoc. Os resultados indicam que o CCN, no período analisado, era reconhecido por seus usuários como um espaço de acolhimento ante a uma organização acadêmica heterogênea, marcada por preconceitos. São discutidas as limitações e as possibilidades de intervenção a partir do uso do CCN, e uma agenda propositiva para a ADAC, com foco na gestão da diversidade.

Palavras-chave: Relações étnicas e raciais. Identidade social. Racismo. Inclusão social.

Abstract: In 2003, the University of Brasília adopted a policy of affirmative action for black people, the System of Quotas for Blacks. In 2004 the Advisory for Diversity and Support to Quota Holders was created. Faced with the demands of the social movement for a support room for students, the Black Conviviality Center was developed, a space opened to the entire academic community. This article presents the experience of the Advisory to 2008 and analyzes the challenges of conviviality between quota students and academic space, through a qualitative research on perceptions, feelings and expectations about the Center, in the form of questionnaires which contained an evocation question to the Center, applied to 35 college students from the System of Quotas for Blacks who attended the Center. The evocation data were analyzed using the software Evoc. The results indicate that the Center, in the analyzed period, was recognized by its users as a welcoming space, compared to a heterogeneous academic organization, marked by prejudices. The limitations and possibilities of interventions for the use of CCN are discussed, and an agenda for the Advisory is proposed, with a focus on diversity management.

Keywords: Racial and ethnic relations. Social identity. Racism. Social inclusion.

Resumen: En 2003, la Universidad de Brasilia adoptó una política de acciones afirmativas para personas negras, el Sistema de Cotas para Negros. En 2004, fue creada la Asesoría de Diversidad y Apoyo a los Cotizantes - ADAC. Ante la demanda del movimiento social por una sala de apoyo a los estudiantes, se desarrolló el Centro de Convivencia Negra - CCN, espacio abierto a toda la comunidad académica. El presente artículo presenta la experiencia de la ADAC hasta 2008 y analiza los desafíos de la convivencia entre estudiantes cotizantes y el espacio académico a partir de una investigación cualitativa sobre percepciones, sentimientos y expectativas acerca del CCN, en la forma de cuestionarios con una pregunta de evocación al CCN, aplicados a 35 estudiantes universitarios oriundos del Sistema de Cotas para Negros asistentes al CCN. Los datos de evocación fueron analizados utilizando el software Evoc. Los resultados indican que el $\mathrm{CCN}$, en el período analizado, era reconocido por sus usuarios como un espacio de abrigo ante a una organización académica heterogénea, marcada por prejuicios. Son discutidas las limitaciones y las posibilidades de intervención desde el uso del CCN, y una agenda de propuestas para la ADAC, con foco en la gestión de la diversidad.

Palabras clave: Relaciones étnicas y raciales. Identidad social. Racismo. Inclusión social.

Há várias conceituações para a diversidade humana, sob a perspectiva psicossocial. Ela pode ser entendida como a representação, em um sistema social, de pessoas com diferentes identidades grupais que têm significações culturais distintas (Cox, 1994) ou ainda como um misto de pessoas com identidades grupais diferentes dentro do mesmo sistema social (Nkomo \& Cox, 1999).

A diversidade é um componente fundamental da identidade social das pessoas, "parte do autoconceito dos indivíduos que deriva do seu conhecimento de pertencimento a um grupo social, associado à significância emocional desse pertencimento" (Tajfel, 1982, p. 24): sabemos quem somos porque há pessoas diferentes de nós (Galinkin, 2003). Não existe identidade social sem diversidade; uma é indissociável da outra na constituição de quem somos, como seres humanos (Allport, 1954).

Refletindo sobre essas características 
O objetivo da gestão da diversidade, considerando-se um ambiente organizacional diverso, é o de incluir pessoas de diferentes culturas, raças, gêneros, orientações sexuais, classes sociais, nacionalidades, estilos e outros atributos (Torres \& Pérez-Nebra, 2004). psicossociais que fundamentam, circundam, potencializam ou obstruem o pleno desenvolvimento da diversidade humana, propõe-se aqui defini-la como o conjunto de relações interpessoais e intergrupais explícitas ou implícitas, em um determinado sistema social, que são intermediadas pela relação entre as identidades sociais e a dominância social presentes nesse sistema.

Os grupos e organizações, quando adotam perspectivas e enfoques de pessoas com identidades sociais e culturais distintas, também se tornam diversas (Thomas \& Ely, 2002; Cox \& Blake, 1991). O objetivo da gestão da diversidade, considerando-se um ambiente organizacional diverso, é o de incluir pessoas de diferentes culturas, raças, gêneros, orientações sexuais, classes sociais, nacionalidades, estilos e outros atributos (Torres \& Pérez-Nebra, 2004).

O presente artigo objetiva apresentar uma experiência de gestão da diversidade (Assessoria de Diversidade e Apoio aos Cotistas) em uma instituição de ensino superior brasileira (Universidade de Brasília), entre 2004 e 2008, e analisar os desafios da convivência entre estudantes oriundos de um sistema de inclusão no espaço acadêmico, tendo como objetivo, junto aos profissionais de Psicologia, contribuir para a construção de uma consciência acerca dos processos psicossociais de pessoas negras, em relações com negros e não negros, em um contexto histórico e cultural que, ao reconhecer desigualdades de cunho etnicorracial, desenvolveu formas de enfrentamento.

\section{Diversidade etnicorracial e desigualdade no Brasil}

A heterogeneidade da população brasileira deveria, a priori, estar refletida na demografia universitária, já que esta se compõe de organizações que visam a atender aos anseios de todo o território nacional. Isso não ocorre sem que haja alguma forma de intervenção na lógica segregacionista que orienta as relações raciais em nossa sociedade (Fernandes, 2007; Paixão, 2004).

O racismo, tanto quanto outras expressões discriminatórias, como a homofobia, o machismo, a xenofobia, etc, tem sido considerado, de forma genérica, como uma expressão elaborada de fobia, decorrente do processo cultural e da alta elaboração cerebral do ser humano (Guindon, Green, \& Hanna, 2003). Assim, como um tipo complexo de fobia, o racismo tem entre seus elementos o medo do contato com pessoas negras.

Tal sentimento pode repercutir na autoimagem da pessoa discriminada, que pode, inclusive, utilizar-se de artifícios para esconder aspectos considerados estigmatizantes de sua aparência e/ou identidade social (Goffman, 1988). No caso do racismo brasileiro, o fenômeno do branqueamento é representativo desse problema (Bento, 2002).

Trazendo a concepção de racismo para o campo dos processos psicossociais mais complexos, pode-se defini-lo especificamente como um conjunto de estereótipos, preconceitos e discriminações de cunho depreciativo (Pérez-Nebra \& Jesus, 2011), relacionado a características fenotípicas e/ou étnicas de pessoas e grupos, que incorrem na hierarquização e na exclusão de pessoas e grupos com relação a outros, tanto em nível individual quanto grupal, coletivo e institucional (Lima \& Vala, 2004).

A atitude do preconceito se aproxima, em termos de mobilização psíquica, da experiência de fobias específicas e, portanto, do sentimento do asco, do nojo, que, no contexto das relações humanas, pode ser definido como uma sensação extrema de repulsa interpessoal (Jesus, 2011).

Reconhecendo-se a histórica estratificação 
social constitutiva da formação brasileira (Damatta, 1983, 1986, 1991), a Universidade de nosso país, a fim de implementar mudanças, precisa lidar com o elevado grau de resistência dos brasileiros a processos de mudança em curto prazo (Hedler \& Lima, 2003), influenciado diretamente pela percepção de envolvimento e de compromisso dos dirigentes e de grupos formadores de opinião, porque, para os parâmetros culturais brasileiros, diferentemente dos de países individualistas, como os Estados Unidos (Hofstede, 1980), o limite de aceitação cultural da ideia de inclusão é o de que diversidade não é exclusão, e muito menos gueto, e uma vantagem cultural é a de que os brasileiros têm a capacidade de tolerar mudanças de longo prazo (Torres \& Dessen, 2008).

Compreender e recompor relações interpessoais degradadas envolve, para além de aspectos psicossociais, uma dimensão político-programática que se caracteriza pela produção e pela disseminação de informações sobre as diferentes experiências de vida, pela ampliação das potencialidades individuais, pelo investimento em ações e programas que identifiquem práticas discriminatórias e possibilitem a formulação de mecanismos de respeito às diferenças (Jesus, 2011; Pérez-Nebra \& Jesus, 2011).

É indicado, para que haja mudanças sustentáveis e não apenas conjunturais nas desigualdades sociorraciais no Brasil, um prazo longo de priorização de estratégias orientadas por firmes fundamentos teóricos, em sintonia "com os anseios das grandes massas de afro-descendentes excluídos e marginalizados" (Moreira, 2003, p. 63).

\section{Sistema de Cotas para Negros na UnB}

A Universidade de Brasília - UnB deu uma resposta a essa questão no dia 6 de junho de 2003, no que tange à comunidade universitária, com a aprovação, pelo seu Conselho de Ensino, Pesquisa e Extensão CEPE, do Plano de Metas para a Integração Social, Étnica e Racial da Universidade de Brasília (Carvalho \& Segato, 2002), que estipulava a criação do Sistema de Cotas para Negros no vestibular da universidade, destinando, durante um período de 10 anos, $20 \%$ do total de vagas de cada curso oferecido nos vestibulares a candidatos negros de cor preta ou parda.

A implantação do Sistema de Cotas para Negros pela UnB foi considerada uma conquista da população brasileira e um marco histórico para a Universidade, primeira instituição pública federal de ensino superior a atuar proativamente, por decisão autônoma de sua comunidade acadêmica, ao encontro da ampliação efetiva do acesso da população negra ao ensino superior (Morhy, 2004).

O Sistema busca romper com a prática segregacionista de se valorizar apenas um segmento étnico na construção do pensamento dos problemas nacionais, considerando-se que, apesar de pretos e pardos constituírem $45 \%$ da população brasileira na época da implantação do Sistema (Henriques, 2001), eram identificados apenas $2 \%$ de estudantes negros na universidade (Paixão, 2004). O Sistema de Cotas para Negros tem, portanto, uma importância estratégica para a construção de um Brasil efetivamente democrático.

Entretanto, apenas aumentar a heterogeneidade em um ambiente, criando diversidade, não é suficiente. Diversidade não é sinônimo de pluralismo e de inclusão imediatos (Torres \& Pérez-Nebra, 2004). O caráter estrutural da política afirmativa adotada pela UnB demanda uma série de desafios particulares que garantam a inclusão efetiva, transcendendo o acesso para garantir a permanência qualificada dos indivíduos. 
"todos nós somos uma mesma equipe, com as nossas diferenças - e não apesar delas" (Torres \& Pérez-Nebra, 2002, p. 13).
Dado o caráter estrutural do racismo, que apresenta vários desafios para o ingresso e para a permanência dos estudantes negros, foi criada uma Assessoria de Diversidade e Apoio aos Cotistas - ADAC (Mulholland, 2006a), com a finalidade de enfrentar as demandas relativas ao objetivo político e estratégico da UnB em valorizar as diferentes dimensões da diversidade.

\section{Assessoria de diversidade e apoio aos cotistas}

As ações afirmativas objetivam a promoção de grupos não atingidos pelas políticas de caráter universal, em nome da efetivação do princípio constitucional de igualdade (Gomes, 2001). A UnB se transformou em um símbolo dessas iniciativas ao aderir à política afirmativa para inclusão dos negros no ensino superior.

Incluir grupos sociais diferentes em um espaço antes homogêneo é passo necessário para a valorização da diversidade, porém não é suficiente. Para além do acesso, a gestão dessa diversidade no sentido de que a comunidade a respeite e a agregue a si é importante para que os novos atores institucionais se sintam parte dela, e os estabelecidos os recebam em suas comunidades.

A discussão sobre o gerenciamento da diversidade nas organizações remete diretamente aos paradigmas de diversidade que podem ser adotados pelas organizações, e esses paradigmas criam uma filosofia para o gerenciamento da diversidade (Thomas \& Ely, 2002), entendendo-se que o objetivo final da gestão da diversidade é a inclusão. São reconhecidos três paradigmas de diversidade: (1) discriminação-e-justiça, (2) acesso-elegitimidade e (3) aprendizagem-e-efetividade.

No primeiro paradigma, denominado discriminação-e-justiça, a inclusão de pessoas diferentes na organização é tida apenas como uma forma de justiça social, o cumprimento de normas estabelecidas, a fim de aumentar a representatividade, na organização, da diversidade existente na sociedade (Thomas \& Ely, 2002). Pode-se enquadrar a iniciativa da UnB em adotar o Sistema de Cotas para Negros nesse paradigma, que é um primeiro passo para a valorização da diversidade etnicorracial, mas ainda insuficiente.

O segundo paradigma, acesso-e-legitimidade, encontra-se em um nível mais elaborado de reconhecimento do valor da diversidade, apesar de não ser o ideal, pois reconhece a força crescente dos grupos historicamente discriminados, de modo que o seu acesso à organização é dado em termos de negócios, como forma de mostrar à sociedade que a empresa adota a diferença, mesmo que ainda seja pautada pela visão do outro como exótico (Thomas \& Ely, 2002).

O paradigma mais complexo, aprendizageme-efetividade, é o que se busca quando se gerencia a diversidade. Após se ter reconhecido a necessidade de se fazer justiça social (discriminação-e-justiça) e de reconhecer o valor das diferenças culturais (acesso-elegitimidade), é necessário transformar as diferenças em uma característica orgânica da organização e dos grupos que a compõem, de modo que todas as pessoas sejam tratadas de forma justa e com oportunidades iguais, independentemente de suas diferenças, e que suas opiniões e perspectivas sejam consideradas igualmente parte dos valores, normas, processos e metas da organização, a ponto de os integrantes dessa organização poderem afirmar que "todos nós somos uma mesma equipe, com as nossas diferenças - e não apesar delas" (Torres \& Pérez-Nebra, 2002, p. 13).

A prática da gestão da diversidade, porém, não é disseminada nacionalmente (Fleury, 2000), apesar de haver inúmeras carências 
no modo de lidar com as questões de diversidade em função de o Brasil ser cultural e demograficamente diverso. No que se refere às dezenas de instituições públicas de ensino superior que implantaram ações afirmativas, por exemplo, até a criação da ADAC, nenhuma havia criado um órgão especificamente para gerir os seus sistemas.

Com vistas a centralizar a gestão do Sistema de Cotas para Negros e fomentar políticas para a diversidade, em dezembro de 2005, foi apresentada à vice-reitoria da UnB a proposta de criação da ADAC, projeto que foi aceito, e criado o cargo de assessoria então vinculado à vice-reitoria. Os trabalhos foram iniciados em março de 2005. Posteriormente, em 14 de março de 2006, após transferência para o gabinete do Reitor, foram oficializadas a criação e as atribuições da Assessoria, a primeira estabelecida em uma instituição pública brasileira para a gestão da diversidade (Mulholland, 2006a).

O projeto da ADAC foi criado partindo da premissa que o paradigma a ser adotado para sua realização deveria ser o da aprendizageme-efetividade, de modo que a convivência entre os estudantes oriundos do Sistema de Cotas para Negros e os demais integrantes da UnB, apesar de ter-se originado de um programa orientado pelo paradigma discriminação-e-justiça, precisava ser trabalhada junto à comunidade de modo a que os novos integrantes não fossem vistos apenas como pessoas colocadas na universidade por força de lei, ou como exóticas (acesso-e-legitimidade), mas como membros efetivos e com contribuições à universidade igualmente ricas às dos demais.

Tendo-se em vista a agenda de inclusão estimulada pelas ações afirmativas, fazia-se mister para a ADAC, além de acompanhar o desenvolvimento dos estudantes ao longo do curso, reiterar a força de nossos laços socioculturais. Foi criado um referencial físico que auxiliasse esses propósitos: o Centro de Convivência Negra - CCN.

\section{Centro de Convivência Negra}

O CCN, espaço voltado para o debate de questões etnicorraciais, coordenado pela ADAC, foi criado em 2005 (Mulholland, 2006b), objetivando sensibilizar a comunidade acadêmica para a temática da negritude e da diversidade, disseminando os valores da igualdade e da justiça, e para que os estudantes oriundos do Sistema de Cotas para Negros tivessem acesso a informações e a formação a respeito da importância da sua presença coletiva na universidade.

A missão do $\mathrm{CCN}$ foi descrita no Projeto Detalhado de Criação do Centro de Convivência Negra, apresentado à direção da vice-reitoria em 10 de fevereiro de 2005, como "oferecer ambiente e serviços de apoio aos universitários negros, especialmente aos que ingressarem pelo Sistema de Cotas para Negros" (Jesus, 2005, p.1). Considerando as metas institucionais, foram visados dois objetivos específicos para o $\mathrm{CCN}$ :

estimular a identificação do estudante negro com a universidade e com os demais membros de seu grupo, aprimorando seu auto-conhecimento e fortalecendo a percepção de sua identidade social como pessoa negra; combater o racismo a partir da presença negra representada fisicamente e por meio de contínuas atividades de cunho acadêmico e cultural, de intervenção prática na vida da UnB (Jesus, 2005, p. 3)

A meta era formar um ambiente de investimento na diversidade, por meio da valorização das pessoas negras e de sua figura na vida acadêmica, considerandose as estratégias adotadas pela gestão contemporânea da diversidade cultural nas organizações (Torres \& Pérez-Nebra, 2004). A equipe do CCN foi constituída, sob coordenação da ADAC, por servidores 
técnico-administrativos, prestadores de serviço e estagiários com perfis formativos e profissionais em diferentes áreas, em especial os provenientes das Artes e das Ciências Humanas e Sociais, tais como Antropologia, Arquivologia, Artes Cênicas, Artes Plásticas, Biblioteconomia, Comunicação, Pedagogia, Psicologia, Sociologia e Terapia Ocupacional, ao longo dos 4 (quatro) anos abordados neste estudo. Um fator considerado primordial na aplicação dos indicados ao trabalho no CCN era seu apoio à política afirmativa adotada pela instituição.

Para o trabalho da equipe, na época, foi adotado um estilo de liderança democrático, cuja ênfase era orientada pela participação no processo decisório tanto da líder (a assessora de Diversidade e Apoio aos Cotistas da época) quanto dos subordinados, com foco mais nas relações entre eles do que nas tarefas (Chiavenato, 2004), em consonância com os modelos apontados por Kinicki e kreitner (2006) como eficazes no contexto contemporâneo, os quais também incluiam o uso de motivação extrínseca (reforços positivos e negativos contingentes ao desempenho) e o incentivo, por parte da liderança, a que os trabalhadores perseguissem objetivos organizacionais em consonância com seus próprios interesses.

Assim, compôs-se o CCN com uma equipe de trabalho instruída quanto às metas de inclusão social, étnica e racial da UnB e orientada a refletir sobre a sua contribuição para o futuro da universidade.

A criação do $\mathrm{CCN}$ se baseou no entendimento de que a discussão sobre ações afirmativas no Brasil indica um momento histórico de revisão dos parâmetros raciais do País (Silvério, 2002), o que implica a possibilidade de se criar espaços de valorização da diversidade. O Centro não foi criado para ser um gueto dos estudantes oriundos do Sistema, mas um espaço de valorização da presença negra na universidade que, no afã de implementar mudanças, precisa lidar com as resistências culturais às mudanças das relações sociais (Hedler \& Lima, 2003).

Esperava-se que o Centro, em sua plena capacidade, pudesse se tornar um espaço de debate para toda a comunidade acadêmica, articulando os grupos de opinião existentes na UnB a favor das metas de inclusão racial e da formação de um ambiente de valorização da diversidade, nesse caso, pelo combate ao racismo, por meio da inclusão positiva do negro e de sua figura na vida acadêmica. Visava-se ao alcance de dois benefícios com o CCN:

um espaço para o estudante negro identificar-se com a universidade e com os demais membros de seu grupo, aprimorando seu autoconhecimento e fortalecendo a percepção de sua identidade social como pessoa negra, o que redunda em um processo de inserção social e fortalecimento do movimento negro em prol dos direitos humanos, organizado ou não, e (...) uma forma efetiva de se combater o racismo causado por condicionamento vicariante (observação de outras pessoas) e por aprendizagem social, visto que, instalado na estrutura da Universidade, o CCN expõe os demais estudantes universitários à presença negra (Jesus, 2005, p. 7)

Era esperado que o racismo existente fosse enfraquecido comportamentalmente, em decorrência da impossibilidade de se negar a presença de pessoas negras na universidade, incluindo-se aí a participação do CCN como espaço significativo na vida da UnB. O CCN abarcou várias manifestações culturais e acadêmicas ligadas ao pensamento negro contemporâneo.

\section{Resultados alcançados}

Considerando-se a literatura em avaliação e monitoramento, pode-se definir o presente artigo como uma avalição ex post (de resultados e impactos), somativa (avaliação final para auxiliar futuras decisões e intervenções) e interna (realizada dentro da organização gestora do projeto por pessoa conhecedora da disciplina, mas não diretamente responsável 
por sua execução, tendo em vista que o período de gestão analisado foi concluído), conforme Rua (2007).

Trabalhos comportamentais no campo do tratamento de fobias específicas indicam elevada efetividade do processo de combate ao racismo por exposição, com diminuição no grau de racismo apresentado pela comunidade universitária (Marshall, 1988; Marks, 1987), melhoria significativa no grau de racismo em torno de $70 \%$ a $85 \%$ (Marks, 1987) e resultados positivos de inclusão racial que podem ser mantidos em longo prazo (Lidell, Fazio, Blackwood, \& Ackerman, 1994).

Apesar de os níveis de análise entre a clínica e a organização serem diferentes (na clínica se trata do indivíduo, e na organização, da cultura organizacional), propõe-se que eficácia, no nível da clínica, pode ser referenciada como um indicador de que é possível haver ganhos sociais no nível das organizações, desde que se encontrem metodologias adequadas e eficazes.

Desde sua criação, a Assessoria realizava ações contínuas de acompanhamento e de apoio aos estudantes cotistas. Todas as ações planejadas durante o período descrito no presente artigo foram implementadas, conforme enumeração na Tabela 1.

Tabela 1. Histórico de ações da ADAC

ANO AÇÕES

2004 Desenvolvimento e implementação das metas e da estrutura da Assessoria Coordenação da monitoria da mostra Abdias Nascimento 90 Anos: Memória Viva, empregando estudantes cotistas

2005 Criação do conteúdo do site do Sistema de Cotas para Negros Implantação física do projeto do CCN

Negociações de vagas de estágio e pesquisa, com empresas e órgãos públicos, voltadas para estudantes cotistas

Participação na banca examinadora de candidatos ao Sistema de Cotas para Negros Gestão do processo de acesso dos estudantes cotistas

Divulgação do Sistema de Cotas para Negros à comunidade, por meio de fôlders, cartazes e outdoors

Representação da vice-reitoria e da reitoria em eventos locais e nacionais

2006 Inserção de estudantes no projeto Kalunga, de desenvolvimento de ações para comunidades quilombolas

Participação na reestruturação da banca examinadora de candidatos ao Sistema de

Cotas para Negros

Presidência da comissão organizadora do Seminário Nacional de Universidades com

Sistemas de Cotas para Negros

Criação e aplicação do programa Cotistas nas Escolas, de sensibilização sobre o

Sistema de Cotas para Negros no ensino médio público

Realização do Mês da Consciência Negra

2007 Realização da Semana da Arte Negra

Recebimento de prêmio em ações afirmativas pela Mostra Internacional do Cinema Negro, em nome da UnB

Apoio à realização na UnB de seminários do Ministério da Educação e do Ministério da Saúde, empregando estudantes cotistas

Realização da Semana Acadêmica do CCN, de apresentação de trabalhos em raça/etnia

2008 Realização de palestras em universidades sobre as ações afirmativas na UnB

Organização de seminário sobre igualdade racial da Câmara dos Deputados 
Detalhando-se os resultados quantitativos e qualitativos da criação da ADAC e do CCN, no período de 2004 a 2008, destacaram-se: acompanhamento acadêmico de todos os 2.332 estudantes cotistas da UnB constantes no período, por meio de acesso ao banco de dados de rendimento acadêmico do Sistema de Administração Acadêmica - SAA; negociação de 40 vagas para estudantes cotistas no programa de estágio do Superior Tribunal de Justiça - ST), de 30 vagas para pesquisa no projeto Kalunga e de 25 no programa Cotistas nas Escolas; articulações diretas para apoio ao programa Brasil Afroatitude, que funciona em espaço próprio no $\mathrm{CCN}$ e disponibilizava 55 bolsas de pesquisa para estudantes cotistas envolvidos em pesquisas e intervenções em saúde, prevenção às DST/AIDS e à promoção da consciência negra; produção de relatórios técnicos sobre a evasão de estudantes cotistas, o perfil acadêmico e profissional dos formandos cotistas (atualmente formados) e o aperfeiçoamento do processo seletivo do Sistema de Cotas para Negros; desenvolvimento de conteúdo para portal informativo sobre o Sistema de Cotas, a Assessoria, o Centro e questões relativas à consciência negra; realização de eventos de valorização da diversidade para centenas de pessoas e parcerias firmadas com dezenas de instituições nacionais e internacionais, públicas e privadas, como a Associação Nacional de Coletivos de Empreendedores Afro-Brasileiros - ANCEABRA, para cujo banco de talentos estudantes cotistas encaminhavam currículos.

Os recursos materiais e financeiros, no período tratado (2004-2008), eram oriundos do gabinete do Reitor. Eventualmente, havia apoio de outros órgãos da UnB ou de entidades externas quando da realização de eventos específicos, como visitação a escolas e ensino médio para divulgar informações sobre o acesso ao ensino superior pelo Sistema de Cotas para Negros.
A equipe de apoio da ADAC mudou muito ao longo desses anos. No começo, contava com apenas com dois estagiários; em 2006, chegou-se a ter o apoio de vinte e cinco. Em 2007, foi formada uma equipe permanente composta por um assistente administrativo, uma prestadora de serviços e dois estagiários, além da então assessora.

Considera-se que as atividades da $\mathrm{CCN}$ eram reconhecidas pela comunidade interna e externa à universidade, no período abordado, pelo fato de que (1) estudantes procuravam o CCN com freqüência, (2) a ADAC era contatada por instituições governamentais para apoio a eventos relativos à diversidade etnicorracial e (3) o site do Sistema de Cotas para Negros ganhou prêmio da Rede DHNet como um dos melhores, em língua portuguesa, em direitos humanos.

\section{Percepções de usuários do $\mathrm{CCN}$}

No último ano da primeira gestão do $\mathrm{CCN}$, 2008, foi realizada uma pesquisa qualitativa sobre percepções, sentimentos e expectativas acerca do $\mathrm{CCN}$, na forma de questionários com uma pergunta de evocação ao Centro, aplicados a 35 (trinta e cinco) estudantes universitários oriundos do Sistema de Cotas para Negros frequentadores do CCN.

Os dados de evocação foram analisados utilizando-se o software Evoc (Vergès, 2000), que correlaciona a frequência das palavras $(\mathrm{F})$ e a ordem em que são evocadas (conhecida pelo termo técnico de ranking médio, a qual denominaremos aqui importância - I: quanto menor o valor do ranking médio, maior a sua importância), em escalas não paramétricas.

Determinou-se que as palavras mais importantes para o grupo pesquisado, como constituintes de sua percepção sobre o CCN, seriam aquelas com maior correlação entre os fatores $\mathrm{F} \mathrm{e} \mathrm{I,} \mathrm{conforme} \mathrm{o} \mathrm{protocolo} \mathrm{de} \mathrm{uso}$ do software (Sá, 1996; Abric, 2001). 
Os resultados serão aqui apresentados de forma sucinta, dado que demandam um artigo empírico específico para seu detalhamento, mas que, apesar disso, podem ilustrar os desafios da convivência entre estudantes cotistas e o espaço acadêmico aventados neste trabalho.

Foi perguntado aos estudantes quais as primeiras palavras ou expressões que lhes vinham à mente quando pensavam no Centro de Convivência Negra. Por meio da evocação, pôde se obter a frequência (F) e a importância (I) dos termos evocados à presença do termo indutor (Centro de Convivência Negra).

Como resultado, identificou-se que as principais palavras associadas ao Centro (com $F$ maior ou igual a 5 e I menor que 3) foram: apoio $(F=5, I=1,40)$, igualdade $(F=5, I$ $=2,40)$ e luta $(F=5, I=2,20)$.

Outras palavras, menos frequentes, porém relevantes ( $\mathrm{F}$ menor que 5 e I menor que $3)$, foram: acolhimento $(F=4, I=2,50)$, afroatitude $(F=3, I=2,00)$, cotas $(F=3$, I $=1,33)$, inclusão $(F=3, I=1,67)$, negritude $(\mathrm{F}=4, \mathrm{I}=2,25)$, oportunidade $(\mathrm{F}=3, \mathrm{I}=$ $1,33)$ e respeito $(F=3, I=2,00)$, estando o termo diferenças $(F=3, I=3,00)$ no limiar dessa colocação periférica ( $F$ menor que 5 e I maior ou igual a 3).

Os resultados indicam que o $\mathrm{CCN}$, no período analisado, era tido por seus usuários como um espaço de acolhimento ante uma organização acadêmica heterogênea, marcada por preconceitos. Os estudantes cotistas, ao se referenciarem ao Centro, reconheciam-no como um espaço de formação de identidade negra, havendo aí um processo de identificação pessoal e social.

\section{Discussão}

É importante problematizar uma associação direta entre a existência da ADAC e do CCN com a aquisição de bolsas, acompanhamento de estudantes, realização de eventos, estabelecimento de parcerias e os demais resultados supracitados, tendo-se em vista que uma relação de causalidade unidirecional pode ser simplista no âmbito das políticas públicas (Cohen \& Franco, 2004).

As realizações da ADAC, por meio do $\mathrm{CCN}$, podem contar com parte de sua explicação no próprio ambiente organizacional favorável a sua consecução, tendo em vista o apoio direto da alta gestão universitária (a ADAC era vinculada ao gabinete do Reitor, que participou ativamente do processo de adoção das cotas); de parceiros institucionais internos, como a SAA; de parceiros externos, como o STJ e o movimento social organizado; de integrantes do corpo docente, discente e técnico-administrativo da universidade; e de autoridades, de modo a estabelecer alternativas de diálogo que não se restringissem ao ambiente acadêmico.

Observou-se a capacidade do Centro de se adaptar a mudanças estruturais frente à crise institucional que afetou a UnB em 2008, que derrubou o então Reitor, mas que, apesar de ter resultado na saída da então assessora, não mudou a dinâmica da política de inclusão racial, sendo preservado o cargo da ADAC e o $\mathrm{CCN}$, apesar de reorganizações e de reposicionamentos, tais como o fato de que o $\mathrm{CCN}$ atualmente está vinculado ao Decanato de Extensão, e não mais ao gabinete do Reitor.

Sugere-se, no que concerne ao enriquecimento do processo de monitoramento e avaliação (Cohen \& Franco, 2004; Pfeiffer, 2005) dos resultados da $\mathrm{ADAC}$ e do $\mathrm{CCN}$, que seja agregado o olhar de profissionais externos à UnB sobre os dados ora apresentados, para uma análise distanciada acerca do grau de alcance dos objetivos da ADAC e do CCN junto aos estudantes cotistas, no período de tempo apresentado. 


\section{Considerações finais}

A ADAC foi uma iniciativa oriunda do projeto de uma servidora pública, psicóloga, aliado a uma conjuntura política e administrativa, que visava a colaborar com a política institucional, valorizando as propostas do movimento social, que foi acatada e fortemente apoiada pela administração. É importante reiterar que foi a primeira assessoria formalizada para a gestão da diversidade universitária e das cotas no Brasil, coordenando um centro multidisciplinar que se propõe a agregar qualquer integrante da comunidade interna e externa, para a implementação de propostas inovadoras e com foco na valorização dos grupos discriminados.

Considera-se que a proposta de criação do $\mathrm{CCN}$ se mostrou realista e viável, no sentido de estimular essa valorização no contexto acadêmico. Esperavam-se resistências, o que não foi claramente identificado, relacionadas ao desafio da convivência, em uma organização heterogênea, marcada por interesses de diferentes grupos e pelo enfrentamento de preconceitos, de pessoas negras com pessoas negras e não negras.

Este relato de experiência, entremeado pela breve descrição de um estudo empírico, demonstra que o conhecimento acerca da experiência da Assessoria e do Centro é relevante para quaisquer profissionais envolvidos com a gestão da diversidade, mas especialmente para psicólogos, que "têm a importante e longa tarefa de colaborar na construção e divulgação de conhecimento sobre os processos de subjetivação dos afrobrasileiros" (André, 2007, p. 159).

Conclui-se, com base em gestão da diversidade, que o caminho para a ampliação da importância da ADAC (não apenas como assessoria, mas também como uma referência de inclusão) e do CCN (não apenas como um espaço físico, mas também como um espaço para reflexões e criações) está na sua disponibilidade para o fomento de debates públicos e na sua receptividade a diferentes dimensões da diversidade, além da etnicorracial.

Jaqueline Gomes de Jesus

Doutora em Psicologia Social, do Trabalho e das Organizações pela Universidade de Brasília,

Brasília - DF - Brasil.

E-mail: jaquelinejesus@unb.br

Endereço para envio de correspondência:

UnB Colina, Bloco C, Ap. 35, Asa Norte. CEP: 70910-900. Brasília, DF 


\section{Referências}

Abric, J-C. (2001). Practicas sociales y representaciones. Ciudad de Mexico: Ediciones Coyacán.

Allport, G. W. (1954). The nature of prejudice. Reading: Addison Wesley.

André, M. C. (2007). Processos de subjetivação em afrobrasileiros: anotações para um estudo. Psicologia: Teoria e Pesquisa, 23(2), 159-167.

Bento, M. A. S. (2002). Branqueamento e branquitude no Brasil. In I. Carone \& M. A. S. Bento (Orgs.). Psicologia social do racismo - estudos sobre branquitude e branqueamento no Brasil (pp. 25-58). Petrópolis, RJ: Vozes.

Carvalho, J. J., \& Segato, R. L. (2002). Plano de metas para a integração social, étnica e racial da Universidade de Brasília. Brasília, DF: Universidade de Brasília.

Chiavenato, I. (2004). Introdução à teoria geral da administração. Rio de Janeiro: Campus.

Cohen, E., \& Franco, R. (2004). Avaliação de projetos sociais. Petrópolis, RJ: Vozes.

Cox, T. Jr. (1994). Cultural diversity in organizations: Theory, research and practice. San Francisco: Berrett-Koehler Publishers.

Cox, T. Jr., \& Blake, S. (1991). Managing cultural diversity: Implications for organizational competitiveness. Academy of Management Executive, 5(3), 45-56.

Damatta, R. (1983). Carnavais, malandros e heróis: para uma sociologia do dilema brasileiro. Rio de Janeiro: Jorge Zahar.

Damatta, R. (1986). Ensaios de sociologia interpretativa. Rio de Janeiro: Rocco.

Damatta, R. (1991). O que faz do brasil Brasil? Rio de Janeiro: Rocco.

Fernandes, F. (2007). O negro no mundo dos brancos. São Paulo: Global (Trabalho original publicado em 1972).

Fleury, M. T. L. (2000). Gerenciando a diversidade cultural: experiências de empresas brasileiras. Revista de Administração de Empresas, 40(3), 18-25.

Galinkin, A. L. (2003). Estigma, território e organização social. Espaço \& Geografia, 6(2), 149-176.

Goffman, E. (1988). Estigma - notas sobre a manipulação da identidade deteriorada. Rio de Janeiro: LTC.

Gomes, J. B. B. (2001). Ação afirmativa e princípio constitucional da igualdade. Rio de Janeiro: Renovar.

Guindon, M. H., Green, A. G., \& Hanna, F. J. (2003). Intolerance and psychopathology: Toward a general diagnosis for racism, sexism, and homophobia. American Journal of Orthopsychiatry, 73(2), 167-176.

Hedler, H. C., \& Lima, S. M. V. (2003). Dimensões culturais e planejamento estratégico. In S. M. V. Lima (Org.). Mudança organizacional: teoria e gestão (pp. 317-339). Rio de Janeiro: Editora FGV.

Henriques, R. (2001). Desigualdade racial no Brasil: evolução das condições de vida na década de 90. Brasília, DF: Instituto de Pesquisas Econômicas Aplicadas.

Hofstede, G. (1980). Cultures consequences: International differences in work-related values. Beverly Hills: Sage.

Jesus, J. G. (2005). Projeto detalhado de criação do Centro de Convivência Negra. Brasília, DF: Universidade de Brasília.

Jesus, J. G. (2011). Atração e repulsa interpessoal. In C. V. Torres \& E. R. Neiva (Orgs.). Psicologia social: principais temas e vertentes (pp. 238-249). Porto Alegre: ArtMed.
Kinicki, A., \& Kreitner, R. (2006). Comportamento organizacional. São Paulo: McGraw-Hill.

Lidell, A., di Fazio, L., Blackwood, J., \& Ackerman, C. (1994). Long-term follow-up of treated dental phobics. Behavior Research and Therapy, 32, 605-610.

Lima, M. E. O., \&Vala, J. (2004). Sucesso social, branqueamento e racismo. Psicologia: Teoria e Pesquisa, 20(1), 11-19.

Marks, I. M. (1987). Fears, phobias and rituals. New York: Oxford University Press.

Marshall, W. L. (1988). Behavioural indices of habituational and sensitization during exposure to phobic stimuli. Behavior Research and Therapy, 26, 67-77.

Moreira, D. (2003). Reflexões sobre mudanças sócio-raciais no Brasil. In Ashoka Empreendedores Sociais e Takano Cidadania (Orgs.). Racismos contemporâneos (pp. 63-92). Rio de Janeiro: Takano Editora Gráfica.

Morhy, L. (2004). Criando oportunidades para todos. Brasília, DF: Centro de Seleção e Promoção de Eventos.

Mulholland, T. (2006a). Ato da Reitoria $n^{\circ}$. 370/2006. Brasília, DF: Universidade de Brasília.

Mulholland, T. (2006b). Ato da Reitoria no. 2162/2006. Brasília, DF: Universidade de Brasília.

Nkomo, S. M., \& Cox, T. Jr. (1999). Diversidade e identidade nas organizações. In S. R. Clegg, C. Hardy, \& W. R. Nord. (Orgs.). Handbook de estudos organizacionais: modelos de análise e novas questões em estudos organizacionais (pp. 334-360). São Paulo: Atlas.

Paixão, M. (2004). O ABC das desigualdades raciais: um panorama da população negra através de uma leitura dos indicadores do Censo 2000. Teoria \& Pesquisa, 42/43, 245-264.

Pérez-Nebra, A. R., \& Jesus, J. G. (2011). Preconceito, estereótipo e discriminação. In C. V. Torres \& E. R. Neiva (Orgs.). Psicologia social: principais temas e vertentes (pp. 217-237). Porto Alegre: ArtMed

Pfeiffer, P. (2005). Gerenciamento de projetos de desenvolvimento: conceitos, instrumentos e aplicações. Rio de Janeiro: Brasport.

Rua, M. G. (2007). Apresentação: monitoramento e avaliação de programas e projetos. Brasília, DF: Escola Nacional de Administração Pública.

Sá, C. P. (1996). Núcleo central das representações sociais. Petrópolis, RJ: Vozes.

Silvério, V. R. (2002). Ação afirmativa e o combate do racismo institucional no Brasil. Cadernos de Pesquisa, 117, 219-246.

Tajfel, H. (1982). Social psychology of intergroup relations. Annual Review of Psychology, 33, 1-39.

Thomas, D. A., \& Ely, R. J. (2002). Making differences matter: A new paradigm for managing diversity. Harvard Business Review on Managing Diversity, 33-66.

Torres, C. V., \& Dessen, M. A. (2008). Valores culturais e a cultura brasileira: desdobramentos teóricos. In M. L. M. Teixeira. (Org.). Valores humanos e gestão: novas perspectivas (pp. 95-116). São Paulo: Editora Senac.

Torres, C. V., \& Pérez-Nebra, A. R. (2004). Diversidade cultural no contexto organizacional. In J. C. Zanelli, J. E. Borges-Andrade, \& A. V. B. Bastos. (Orgs.). Psicologia, organizações e trabalho no Brasil (pp. 441-463). Porto Alegre: ArtMed.

Vergès, P. (2000). Ensemble de programmes permettant I'analyse des evocations: Manuel version 2. Aix-en-Provence: LAMES. 